\title{
Implementasi Promethee Menentukan Kelayakan Produk Ekspor Pada PT. MTCFI
}

\author{
Promethee Implementation Determines the Feasibility of Export Products at PT. MTCFI \\ Juwita Dwirna Puspal, Muhammad Fauzi ${ }^{2}$ \\ ${ }^{1,2}$ Program Studi Sistem Informasi, Fakultas Teknik Dan Ilmu Komputer \\ ${ }^{2}$ Dosen Jurusan Sistem Informasi, Universitas Potensi Utama \\ ${ }^{1,2}$ Universitas Potensi Utama, K.L. Yos Sudarso KM 6,5 No. 3 A Tj. Mulia - Medan \\ E-mail : juwitadwirnapuspa@gmail.com ${ }^{1}$,mfauzixx@gmail.com ${ }^{2}$
}

\begin{abstract}
ABSTRAK
Permasalahan yang dihadapi adalah proses pencatatan/perhitungan masih bersifat semi komputerisasi dan manual, sehingga menyebabkan penumpukan berkas/data-data. Dan dibutuhkan waktu yang cukup lama dalam pencarian data,hal ini sering kali menghambat pekerjaan dan karyawan harus memberikan penilaian pada produk olahaan. Dan ini membuat karyawan sedikit kesulitan dalam pengambilan keputusan menentukan produk yang layak.Tujuan dibangunnya sistem ini dapat membantu dalam menentukan kelayakan produk yang diekspor pada PT. MTCFI yang tepat dan akurat berdasarkan penilaian. Hasil dari penelitian ini Metode promethee sebagai Metode efisien dan sederhana, juga mudah diterapkan dibandingkan dengan metode lain untuk menyelesaikan masalah multiciteria dengan cepat dan tepat sehingga dapat membantu perusahaan dalam menentukan produk yang layak/tidak. Dengan cara memberi bobot masing-masing kriteria dan akan dikumpulkan pada alternatif dan bahasa Pemrograman Visual Basic dengan Database SQL Server. Penelitian ini untuk Membangun sebuah Implementasi Metode Promethee Dalam Menentukan Kelayakan Produk Yang Di Eksporterkomputerisasi untuk mengganti sistem lama yang digunakan di perusahaan.
\end{abstract}

Kata kunci : Sistem Pendukung Keputusan, Menentukan Kelayakan Produk Ekspor, Metode PROMETHEE, SQL Server

\section{ABSTRACT}

The prevailing problem is that the recording / calculation process is still semi-computerized and manual, causing the accumulation of files / data. And it takes a long time to search for data, this often hinders work and employees must provide results on processing products. And this makes employees a little difficult in making decisions to determine which products are feasible. The purpose of building this system can help in determining the feasibility of products exported at PT. Precise and accurate MTCFI based on estimates. The results of this study Promethee method as an efficient and simple method, is also easy to apply compared to other methods to solve multiproblem problems quickly and precisely so that it can help companies determine which products are feasible / not. By giving weight to each criterion and will be collected in the alternative and Visual Basic Programming language with SQL Server Database. This research is to build an implementation of the Promethee method in determining the feasibility of a computerized product to replace the old system used in the company.

Keywords : Decision Support System, Determining the Feasibility of Export Products, PROMETHEE Method, SQL Server

\section{PENDAHULUAN}

Perikanan merupakan sektor ekonomi yang memiliki potensi dan peranan penting bagi perekonomian Indonesia [10]. Dalam era perdagangan sekarang ini, persaingan produk olahan semakin banyak, sangat penting untuk mengutamakan kualitas produk. Apabila tidak 
melakukannya maka bisa tergeser oleh perusahaan lain yang memiliki produk yang sejenis, yang lebih meyakinkan konsumen. Diperlukan standar atau aturan untuk mencapai tingkat kualitas produk olahan [6]. Oleh sebab itu, kita berupaya agar dapat menentukan bahan baku yang memiliki kualitas tinggi dan yang tidak memiliki kualitas [5].Contohnya, kesegaran ikan adalah tolak ukur yang membedakan ikan berkualitas buruk dan ikan berkualitas baik.

PT. Medan Tropical Canning \& Frozen Industries(MTCFI) merupakan perusahaan yang berdiri tahun 1984, bergerak dalam bisnis industri pengolahan produk perikanan untuk ekspor dan bidang pembuatan pemrosesan laut. Bidang bisnis diklasifikasikan berdasarkan proses dibagi menjadi dua, yaitu canning dan frozen. Pengalengan adalah proses dimana bahan makanan laut diproses menjadi suatu makanan dalam kalengan, sementara Beku adalah proses pembekuan produk laut yang tujuannya pada akhirnya akan diekspor. Di perusahaan ini tentunya harus memiliki sistem yang dapat membantu dalam menentukan kelayakan produk. Sistem yang berjalan diperusahaan masih semi-terkomputerisasi dengan Microsoft Excel dan buku dalam proses pencatatan dan pembuatan laporan produksi pengalengan produk. Menentukan produk layak atau tidak layak merupakan salah satu cara untuk meningkatkan pengembangan kualitas produk olahaan ekspor, sehingga dapat menjadi produk yang layak dan dengan adanya menentukan produk yang layak dapat menjadikan salah satu keuntungan bagi perusahaan dan dapat meningkatkan nama baik perusahaan. Dalam menentukan keputusan produk layak, karyawan harus memberikan penilaian pada produk olahan dari nilai yang paling tinggi sampai dengan nilai yang paling rendah. Hal ini membuat karyawan sedikit kesulitan dalam pengambilan keputusan untuk menentukan produk yang layak.

Salah satu metode sistem pendukung keputusan yang multikriteria yaitu Promethee. dikenal sebagai metode sistem pendukung keputusan yang sederhana dan efisien, juga mudah diterapkan dibanding dengan metode lainnya [4] dengan cepat dan tepat sehingga dapat memudahkan perusahaan dalam menentukan produk yang layak.

Untuk itu, peneliti membuat suatu Sistem Pendukung Keputusan dengan menggunakan Metode PROMETHEE dan bahasa Pemrograman Visual Basic dengan Database SQL Server, untuk membuat sistem berbasis komputer yang merupakan alternatif untuk memprioritaskan efektivitas dan efisien dalam menentukan kelayakan produk yang diekspor [4]. Peneliti hanya membahas Kelayakan produk seperti kelayakan produk kemasan ikan. Ikan yang di produksi dengan pengalengan hanya Ikan Cakalang, Ikan Yellowfin, Ikan Dungun, Ikan Deho dan Ikan Tuna yang diekspor pada PT. MTCFI [4]. Penelitian ini bertujuan untuk Membangun sebuah implementasi Metode Promethee Dalam Menentukan Kelayakan Produk Yang Di Ekspor yang terkomputerisasi untuk mengubah sistem yang lama pada perusahaan yang penulis teliti [4].

Berdasarkan penelitian yang dilakukan oleh Safrizal dan Lili Tanti (2015) bertujuan menggunakan metode ini untuk dapat membantu pihak QLTC dalam pengambilan keputusan siswa baru, sehingga dapat memberikan pertimbangan pihak manajemen [7].

Berdasarkan penelitian yang dilakukan oleh Muhammad Fauzi (2015) dengan tujuan untuk menyatukan mahasiswa diberbagai kalangan dalam setiap kelas, manfaatnya mahasiswa jadi terorganisir, meningkatkan kesadaran, kepribadian dan mental yang baik untuk pengembangan psikologis mahasiswa. Untuk memberikan mahasiwa jabatan dibutuhkan beberapa syarat tertentu agar keputusan bisa dianggap adil [2].

\section{METODE PENELITIAN}

Metodologi penelitian digunakan oleh penulis dalam penelitian ini adalah :

1. Metode Penelitian Lapangan (Field Research)

Penelitian ini digunakan untuk memperoleh data dengan cara :

a. Wawancara (Interview)

Metode ini berhadapan dengan pihak terkait untuk mendapatkan informasi yang dibutuhkan seputar penelitian.

b. Pengamatan (Observation)

Mengamati langsung ke objek pembahasan ada di Jalan K.L Yos Sudarso Km. 10.5

Kawasan Industri Medan - 20245. 
c. Sample(Sampling)
Meneliti dan memilih dokumen yang dibutuhkan pada perusahaan.

2. Studi Kepustakaan (Library Research)

Dalam studi-studi literatur ini adalah semua upaya penelitian untuk mengumpulkan atau memperoleh informasi dari buku, esai ilmiah, tesis dan disertasi yang dilakukan di perpustakaan regional.

Dalam melaksanakan pengembangan sistem penulis menggunakan model fishbone dengan tahapan-tahapan berikut:

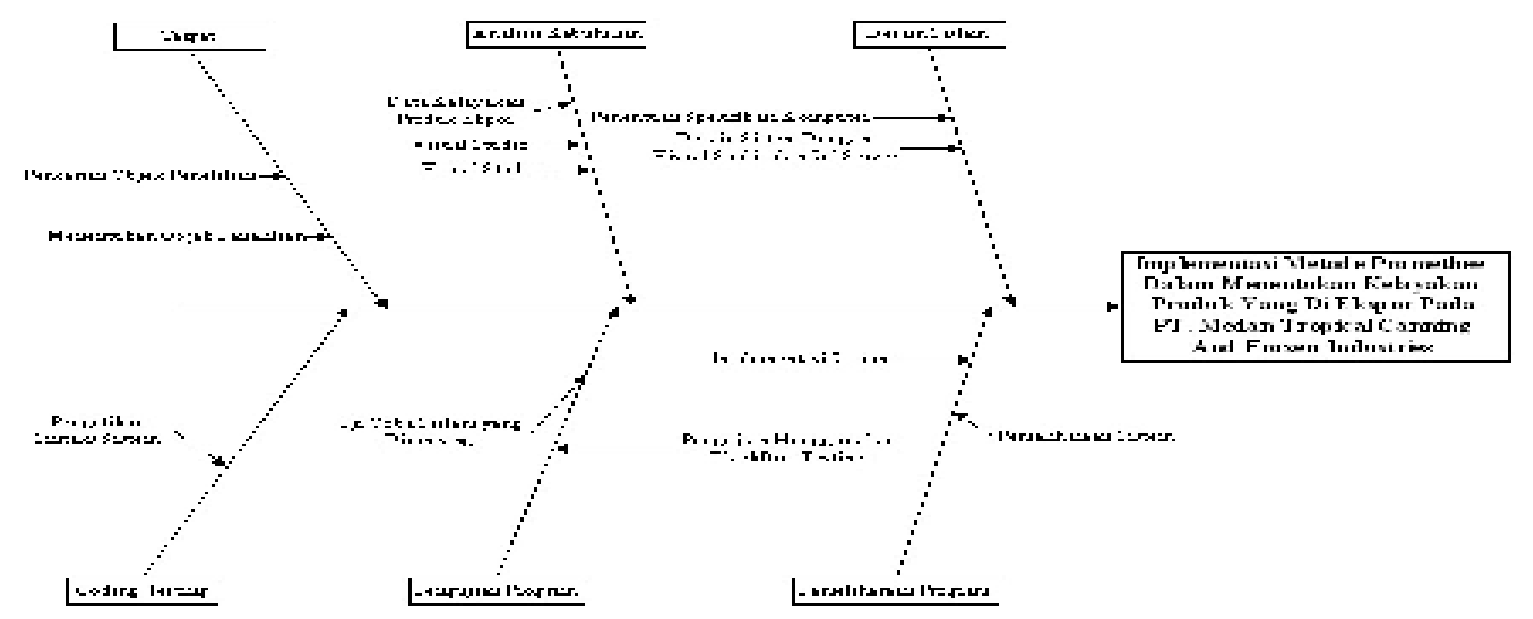

Gambar 1. Diagram Pengembangan Sistem Fishbone

Pengembangan Sistem Diagram Fishbone dapat dijelaskan sebagai berikut:

a. Target Lokasi

Target penelitian ini adalah implementasi dari metode Promethee dalam menentukan kelayakan produk yang diekspor di PT. Industri Canning And Frozen Industries. Penulis berharap bahwa dalam aplikasi menentukan kelayakan produk ini dapat tersistem dengan baik.

b. Anasisis Kebutuhan

melakukan pengumpulan data produk yang diekspor yang akan digunakan untuk sistem pendukung keputusan yang penulis peroleh dari perusahaan. Dalam tahap ini dilakukan verifikasi data dalam proses penerapan metode promethee yang digunakan. Penerapan metode ini nantinya akan disesuaikan dengan aplikasi yang akan digunakan yaitu Visual Studio, sehingga nantinya data yang telah dihitung manual dengan yang tersistem memiliki kesamaan.

c. Desain Sistem

Tahap ini membutuhkan hardware dan software yang sesuai dengan persyaratan sistem sebagai berikut :

1) Spesifikasi Perangkat Keras

hardware yang dibutuhkan adalah komputer dengan spesifikasi ASUS dengan Processor Intel Core i3 4 GB, 2.0 Ghz, Ram 4 GB, Hardisk 500 GB

2) Spesifikasi Perangkat Lunak

software meliputi:Sistem operasi Windows 10 Ultimate 32-Bit, Visual Studio 2010 dan SQL Server 2008.

d. Coding Testing

Tahap ini merupakan mengimplementasikan sistem yang telah melalui proses pengkodean yang akan diterapkan oleh perusahaan. Sistem dibuat sesuai dengan metode yang digunakan, sehingga hasil yang didapat sesuai dengan judul yang dibuat dalam penelitian.

e. Pengujian Program 
tahap ini melakukan pengujian terhadap program sebelum digunakan oleh perusahaan. Untuk menghindari kecacatan terhadap program.

f. Pemeliharaan Program

tahap ini perangkat lunak sistem dibangun memerlukan perawatan terhadap sistem, agar tidak terjadi kerusakan terhadap sistem.

\subsection{Sistem Pendukung Keputusan}

merupakan sistem yang memberikan pemodelan, informasi dan manipulasi data. Sementara sistem keputusan adalah pendekatan sistematis dalam sifat suatu masalah, mengumpulkan fakta, menentukan alternatif yang dihadapi dan melakukan tindakan sesuai dengan perhitungan [2]. Gory dan Scoot-Martoon, mendefenisikan sistem pendukung keputusan untuk membantu tim promosi melakukan suatu keputusan [9].

\subsection{Metode Preference Ranking Organization For Enrichment Evaluation(PROMETHEE)}

PROMETHEE merupakan salah satu metode untuk menentukan prioritas Analisis Multiktriteria. Metode ini cukup sederhana dan efisien, tetapi juga yang mudah diterapkan dibandingkan dengan metode lain untuk menyelesaikan masalah multiciteria [4].

\section{HASIL DAN PEMBAHASAN}

Dalam era perdagangan sekarang ini, dimana persaingan produk olahan semakin banyak, kualitas produk menjadi sangat penting untuk diutamakan. Apabila tidak mengutamakan kualitas produkmaka bisa tergeser oleh perusahaan lain yang memiliki produk yang sejenis, yang lebih meyakinkan konsumen. Untuk mencapai tingkat kualitas produk olahan maka diperlukan standar atau aturan [6]. Oleh sebab itu, kita diharuskan memilih bahan baku yang mempunyai kualitas tinggi dan kualitas rendah [5]. Contohnya kesegaran ikan merupakan tolak ukur yang membedakan ikan berkualitas buruk dan ikan berkualitas baik.

Menentukan produk layak atau tidak layak merupakan salah satu cara untuk meningkatkan pengembangan kualitas produk olahaan ekspor, sehingga dapat menjadi produk yang layak dan dengan adanya menentukan produk yang layak dapat menjadikan salah satu keuntungan bagi perusahaan dan dapat meningkatkan nama baik perusahaan. Dalam menentukan keputusan produk layak, karyawan harus memberikan penilaian pada produk olahan yang bernilai tinggi sampai rendah. Hal ini membuat karyawan sedikit kesulitan dalam pengambilan keputusan untuk menentukan produk yang layak.

1. MenentukanAlternatif

Tabel 1. Alternatif

\begin{tabular}{|ll|}
\hline Kode & \multicolumn{1}{c|}{ Altermatt } \\
\hline $\mathrm{AO1}$ & lkan Cakalang \\
\hline $\mathrm{AOC}$ & lkan Yellow fiu \\
\hline $\mathrm{AOS}$ & Tkan Dimgur \\
\hline $\mathrm{AO} 1$ & Ikan Deho \\
\hline $\mathrm{AOS}$ & Ikan Turia \\
\hline
\end{tabular}

\section{MenentukanKriteria}

Tabel 2. Kriteria

\begin{tabular}{|l|l|}
\hline Kode & \multicolumn{1}{|c}{ K riteria } \\
\hline KI & Kemampaken \\
\hline K2 & Dsu \\
\hline K3 & Disging \\
\hline
\end{tabular}

\section{Menentukan Dominasi Kriteria}

Berikut bobot peniliaian pada kasussistem pendukung keputusan menentukan kelayakan produk yang diekspor dengan Metode PROMETHEE.

\section{a. Kenampakan}

Kenampakan adalah wujud/bentukdari ikan. Ikan segar memiliki penampakan yang cerah dan tidak suram. Situasi ini disebabkan oleh tidak banyak perubahan biokimiawi yang terjadi [8]. 
Tabel 3. Kriteria Kenampakan

\begin{tabular}{|c|c|}
\hline Sell Kriteria & Pobon Penifteiait \\
\hline 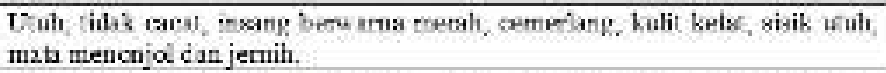 & 9 \\
\hline 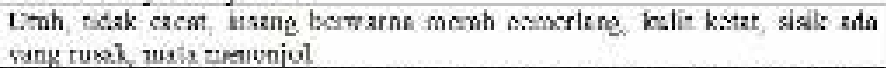 & 7 \\
\hline 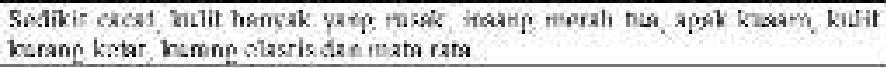 & 5 \\
\hline 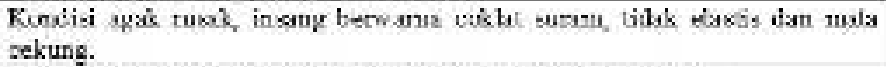 & 3 \\
\hline 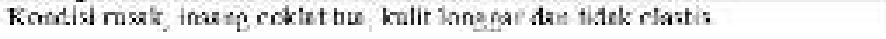 & 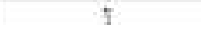 \\
\hline
\end{tabular}

b. Bau

Bau adalah aroma dari ikan. Ikan yang berkualitas memiliki bau yang segar dan ringan.

Bau yang tercium dari ikan segar tidak mengganggu penciuman [8].

Tabel 4. Kriteria Bau

\begin{tabular}{|l|c|}
\hline \multicolumn{1}{|c|}{ Sub Kriteria } & Bobot Pen Ilaian \\
\hline Bau sungat segar & 9 \\
\hline Bau bcurang segar & 7 \\
\hline Bau netral & 5 \\
\hline Sedikit bau ten gik & 3 \\
\hline Bau tengik dan busuk & 1 \\
\hline
\end{tabular}

c. Daging

Menentukan tekstur suatu daging. Ikan yang masih segar, lentur berdaging, jika ditekan dengan jari telunjuk atau ibu jari sehingga tanda akan segera kembali [8].

Tabel 5. Kriteria Daging

\begin{tabular}{|c|c|}
\hline Sub Kriteria & Bebet Penibian \\
\hline $\begin{array}{l}\text { Sayatan daging therah pink/rose twenurut jenis asmgat censerlang. otot } \\
\text { daging sangat podat, elastis, berlemak, jaringan daging tidak pecah. }\end{array}$ & 9 \\
\hline $\begin{array}{l}\text { Sayatan daging memi pinik rose menurut jenis cemerlang, otot daging } \\
\text { padat, elastis, tidak berlemak; jaringan tidak pecah. }\end{array}$ & 7 \\
\hline $\begin{array}{l}\text { Sayatan dagiag merah lasam, kumang cemerlang, otot daging kurang } \\
\text { elastis, sedikit bermimyak dam mulai tumbeh lapisan pelangi di permukan } \\
\text { daging. }\end{array}$ & 5 \\
\hline $\begin{array}{l}\text { Sayatan daging merah kecoklatan, obot daging kurang padat don kurang } \\
\text { elastis, jarngan daging mula pecah. }\end{array}$ & 3 \\
\hline $\begin{array}{l}\text { Sayatas daging sangat kosam, berwama cokkt, daging Jembek sekall dan } \\
\text { joringas daging pecah. }\end{array}$ & 1 \\
\hline
\end{tabular}

Contoh Kasus yang diteliti :

Dalam hal ini, penulis akan mengambil 5 contoh alternatif untuk menentukan kelayakan produk yang diekspor pada perusahaan(MTCFI) dengan langkah-langkah berikut :

Tabel 6. Perhitungan Bobot Alternatif

\begin{tabular}{|c|c|c|c|c|c|}
\hline $\begin{array}{l}\text { Krileria } \\
\text { A trematif }\end{array}$ & $\begin{array}{l}\text { Tkim } \\
\text { Cukulang }\end{array}$ & Tkatn $Y$ ellow fin & Ihari Duragun & Ikan Dehu & Ikan Tuma \\
\hline Kenampakan & 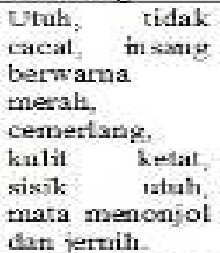 & $\begin{array}{l}\text { Utuh, tidak } \\
\text { catat, insamg } \\
\text { berwana } \\
\text { mezah } \\
\text { cernerlang. } \\
\text { kutit kelat, } \\
\text { sisil asta yang } \\
\text { rusak, mats } \\
\text { menonjot. }\end{array}$ & 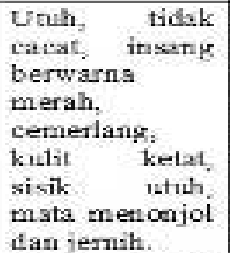 & 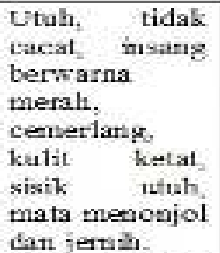 & 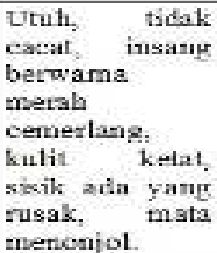 \\
\hline Bad & $\begin{array}{l}\text { Bau barsing } \\
\text { senpt }\end{array}$ & $\begin{array}{l}\text { Bau burang } \\
\text { schar }\end{array}$ & $\begin{array}{l}\text { Bau sangat } \\
\text { segar }\end{array}$ & $\begin{array}{l}\text { Bau Janrang } \\
\text { segrar }\end{array}$ & Bau netral \\
\hline Daging & $\begin{array}{l}\text { Sayatan } \\
\text { ibiping menil } \\
\text { pinkirne } \\
\text { monumat jonis } \\
\text { cemerlang. } \\
\text { otot daging } \\
\text { padat, elastis. } \\
\text { tidak } \\
\text { berlemak, } \\
\text { jaringan tidak } \\
\text { pecah. }\end{array}$ & $\begin{array}{l}\text { Sayatan } \\
\text { claging merah } \\
\text { primk/nose } \\
\text { mevurut jenis } \\
\text { cemerlang. } \\
\text { otot daging } \\
\text { padzt, dastis. } \\
\text { tidak } \\
\text { berlemak. } \\
\text { jaringan tidak } \\
\text { pecah. }\end{array}$ & $\begin{array}{l}\text { Sayatan } \\
\text { taging murah } \\
\text { pimk/nose } \\
\text { monurut jcajs } \\
\text { sangat } \\
\text { cemerlang, } \\
\text { otot dr ging } \\
\text { sangat padat. } \\
\text { elastis. } \\
\text { berlemak, } \\
\text { jaringan } \\
\text { daging tidak } \\
\text { pecah. }\end{array}$ & $\begin{array}{l}\text { Sayatan } \\
\text { tatying merah } \\
\text { pinkirne } \\
\text { monutut jenis } \\
\text { sangat } \\
\text { cemerlang. } \\
\text { otot daging } \\
\text { sangat padat, } \\
\text { elastis, } \\
\text { berlemak, } \\
\text { jsringan } \\
\text { daging tidak } \\
\text { pecah. }\end{array}$ & $\begin{array}{l}\text { Sayatan daging } \\
\text { memah } \\
\text { pink/rose } \\
\text { monurut jenis } \\
\text { oenerlang, otot } \\
\text { daging padat, } \\
\text { elastis, tirak } \\
\text { beclcmak, } \\
\text { jaringan tidak } \\
\text { pecah. }\end{array}$ \\
\hline
\end{tabular}


Tabel 7. Perhitungan Bobot Nilai Alternatif

\begin{tabular}{|c|c|c|c|c|c|c|}
\hline \multirow[t]{2}{*}{ su. } & \multirow[t]{2}{*}{ Ẽaltra } & \multicolumn{5}{|c|}{ Babal Nibal } \\
\hline & & $\begin{array}{c}\text { Ikail } \\
\text { Cahalans }\end{array}$ & 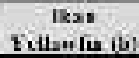 & $\begin{array}{c}\text { IKaE } \\
\text { Duapar \& }\end{array}$ & $\begin{array}{c}\text { 18an } \\
\text { Detavida }\end{array}$ & $\begin{array}{c}\text { Ikan } \\
\text { reare } 13 \text {. }\end{array}$ \\
\hline$T$ & उता & 5 & 7 & 4 & 5 & 7 \\
\hline 2. & 33 & 7 & 7 & $a$ & 7 & 3 \\
\hline 3. & 33 & 7 & 7 & 9 & 3 & 7 \\
\hline \multicolumn{2}{|c|}{ sumbsoul } & 23 & 31 & 27 & 35 & 19 \\
\hline
\end{tabular}

4. Hitung Nilai Preferensi

tahap ini merupakan perbandingan antara alternatif pertama dengan alternatif kedua dikurangi, maka nilai preferensi dihitung sesuai dengan jenis preferensi yang digunakan. Penulis menggunakan fungsi preferensi kriteria yang biasa yang penulis jelaskan sebelumnya. Untuk detail lebih lanjut, anda dapat melihat dalam perhitungan di bawah ini :

Tabel 8. Pola Perhitungan

\begin{tabular}{|l|}
\hline$a b c d e$ \\
\hline$a b-a c-a d-a c$ \\
\hline$b c-b d-b e-b a$ \\
\hline$c d-c e-c a-c b$ \\
\hline$d e-c a-c b-c c$ \\
\hline$e a-e b-e c-e d$ \\
\hline
\end{tabular}

(Usual Criterian) Kriteria Biasa

Dimana :

$$
H(d)=\left\{\begin{array}{l}
0 \text { jika } d \leq 0 \\
1 \text { jika } d>0
\end{array}\right.
$$

$\mathrm{H}(\mathrm{d})=$ fungsi selisih kriteria antar alternative, $\mathrm{d}=$ selisih nilai kriteria $\{\mathrm{d}=\mathrm{f}(\mathrm{a})-\mathrm{f}(\mathrm{b})\}$ [3].

1. $\mathrm{K}_{1}=$ Kenampakan

\begin{tabular}{|c|c|c|c|}
\hline 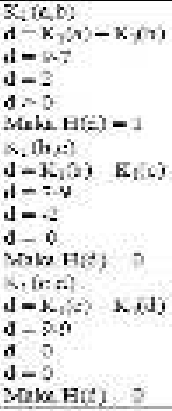 & 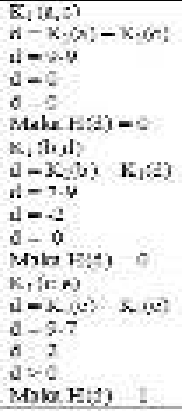 & 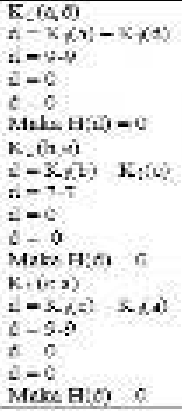 & 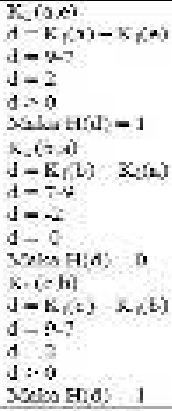 \\
\hline 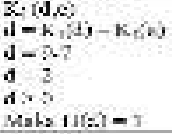 & 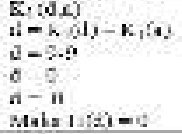 & 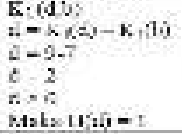 & 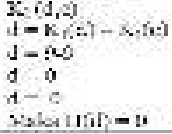 \\
\hline 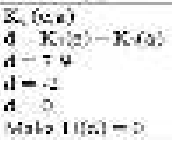 & 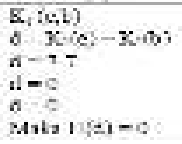 & 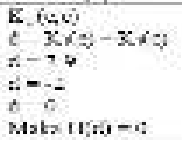 & 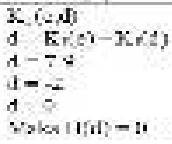 \\
\hline
\end{tabular}

2. $\mathrm{K}_{2}=\mathrm{Bau}$

\begin{tabular}{|c|c|c|c|}
\hline 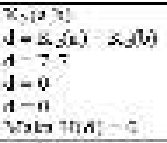 & 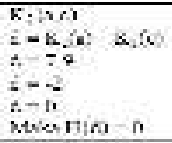 & 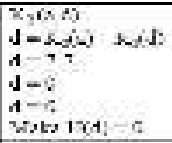 & 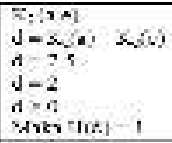 \\
\hline 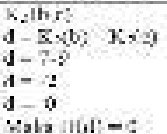 & 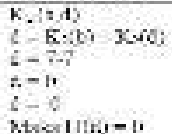 & 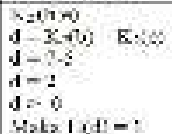 & 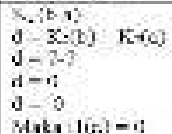 \\
\hline 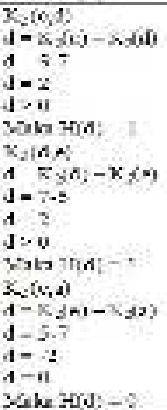 & 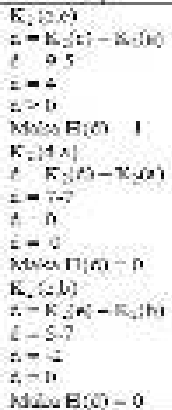 & 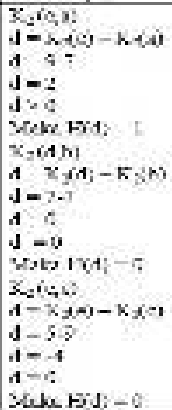 & 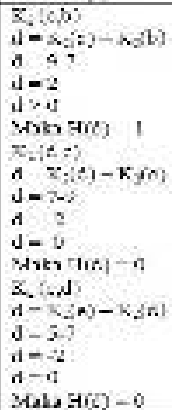 \\
\hline
\end{tabular}




\begin{tabular}{|c|c|c|}
\hline 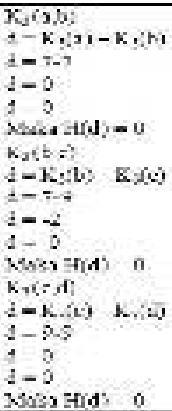 & 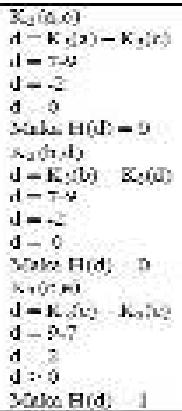 & 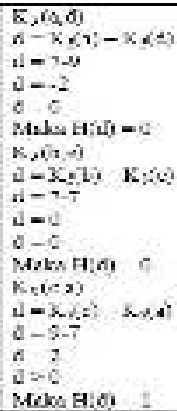 \\
\hline 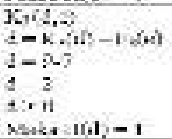 & 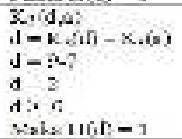 & 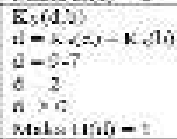 \\
\hline 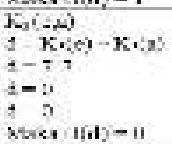 & 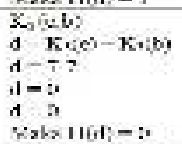 & 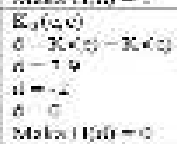 \\
\hline
\end{tabular}

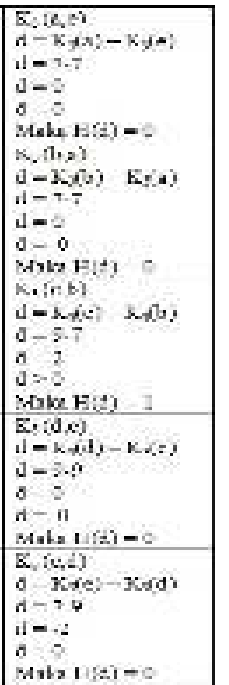

Tabel 9. Tabel Index Preferensi Multikriteria

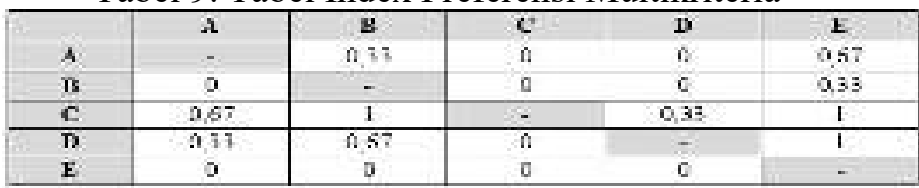

a. Menghitung Leaving Flow

$$
\varphi^{+}(\alpha)=\frac{1}{\mathrm{n}-1} \sum \mathrm{x} \in \mathrm{A} \varphi(\alpha, \mathrm{x})
$$

$1=\frac{1}{4}(0,33+0+0+0,67)$

$=\frac{1}{4}(1)=0,25$

$2=\frac{1}{4}(\mathrm{O},+\mathrm{O}+\mathrm{O}+\mathrm{O}, 33)$

$=\frac{1}{4}(0,33)=0,08$

$3=\frac{1}{4}(0,67+1+0,33+1)$

$=\frac{1}{4}(3)=0,75$

$4=\frac{1}{4}(0,33+0,67+0+1)$

$=\frac{1}{4}(2)=0,50$

$5=\frac{1}{4}(\mathrm{O}+\mathrm{O}+\mathrm{O}+\mathrm{O})$

$=\frac{0}{4}(0)=0$

c. Menghitung Net Flow

$$
\varphi(\alpha)=\varphi^{+}(\alpha)-\varphi^{-}(\alpha)
$$

$1=0.25-0.25=0$

$2=0,08-0,50=-0,42$

$3=0,75-0=0,75$

$4=0,50-0,08=0,42$

$5=0-0.75=-0.75$ b. Menghitung Entering Flow

$$
\varphi^{-}(\alpha)=\frac{1}{n-1} \sum \mathrm{x} \in \mathrm{A} \varphi(\alpha, \mathrm{x})
$$

$1=\frac{1}{(5-1)}(0+0,67+0,33+0)$

$=\frac{1}{4}(1)=0,25$

$2=\frac{1}{(5-1)}(0,33+1+0,67+0)$

$=\frac{1}{4}(2)=0,50$

$3=\frac{1}{(5-1)}(0+0+0+0)$

$=\frac{1}{4}(0)=0$

$4-\frac{1}{(5-1)}(0+0+0,33+0)$

$=\frac{i}{4}(0.33)=0.08$

$5-\frac{1}{(3-1)}(0,67+0,33+1+1)$

$=\frac{1}{4}(3)=0,75$

Tabel 10. Tabel Keputusan Kelayakan Produk

\begin{tabular}{|c|c|}
\hline Range & Jenis Keputusan \\
\hline$<=0$ & Lasak \\
\hline$<0$ & Tidak layak \\
\hline
\end{tabular}

Tabel 11. Hasil Per Rankingan Metode Promethee 


\begin{tabular}{|c|c|c|c|c|c|}
\hline Alternatr & $\begin{array}{l}\text { Leaving } \\
\text { Flow }\end{array}$ & $\begin{array}{c}\text { Ensering } \\
\text { Fbow }\end{array}$ & $\begin{array}{l}\text { Ner } \\
\text { Flow }\end{array}$ & Rangking & Keteraugan \\
\hline Than Cakalang & 0,25 & 0,25 & 0 & 3 & Layalk \\
\hline Ikan Y ellowfin & 0,08 & 0,50 & $-0,42$ & 4 & Tidnk layak \\
\hline Ikan Dungun & 0.75 & $\theta$ & 0.75 & 1 & Layes \\
\hline Tkan Dehe & 0,50 & 0,08 & 0,42 & 2 & Layali \\
\hline Ikan Tuua & 0 & 0,75 & $-0,75$ & 5 & Tidak layal \\
\hline Kesirnpulas & \multicolumn{5}{|c|}{ 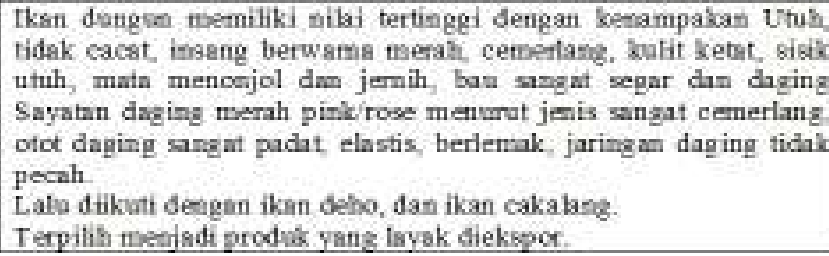 } \\
\hline
\end{tabular}

Dari Tabel 11 diatas maka dapat diperoleh rangking dari masing-masing alternatif. Alternatif Ikan dungun mempunyai Net Flow tertinggi, direkomendasikan untuk menjadi produk yang layak diekspor.

\subsection{Use Case Diagram}

Dalam penyusunan suatu program diperlukan suatu model data yang berbentuk diagram yang dapat menjelaskan suatu alur proses sistem yang akan di bangun [1]. Alur proses sistem dapat digambarkan melalui use case diagram berikut :

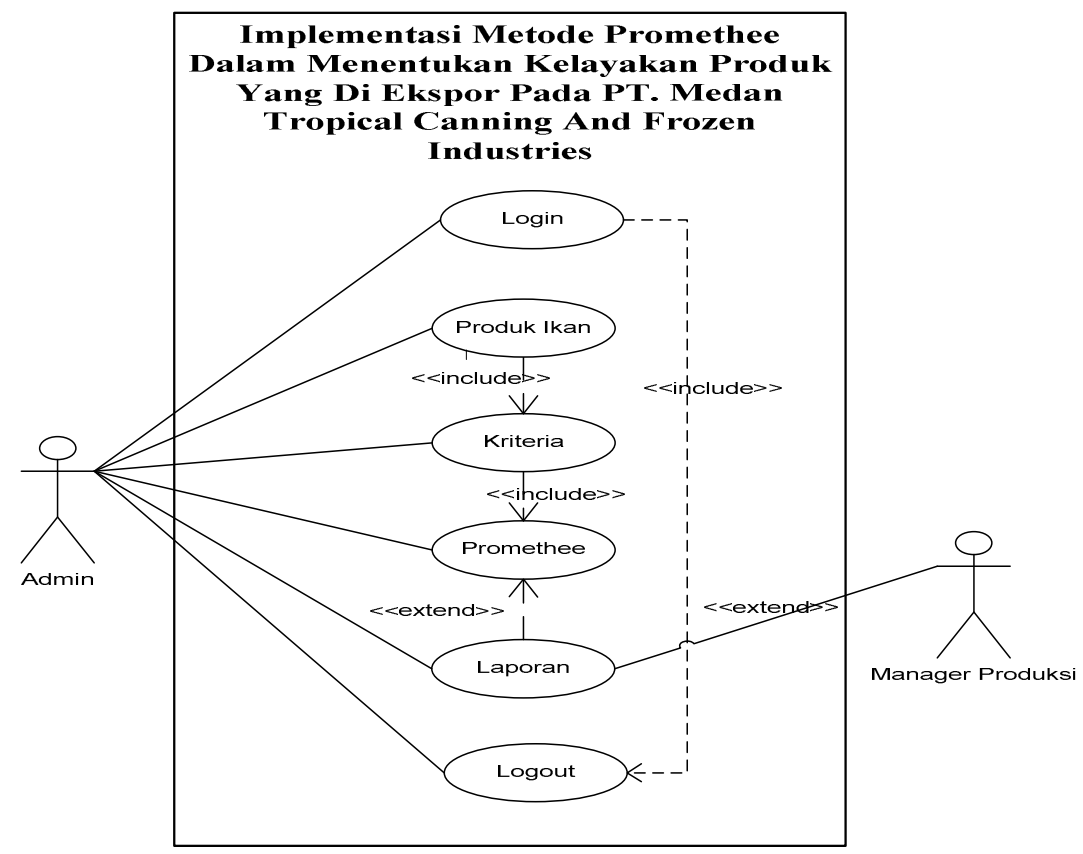

Gambar 2. UseCase Diagram

3.2. Tampilan Hasil

1. Tampilan Form Menu Utama

Form menu utama merupakan tampilan awal atau pembukaan pada aplikasi saat berjalan. Dalam tampilan ini, dapat dilihat bahwa menu-diakses adalah Login, Produk Ikan, Kriteria, Promethee, Laporan, About, Catalog,Logout. Tampilan form menu utama dapat kita ilihat pada gambar 3. berikut ini : 
Gambar 3. Form Menu Utama

2. Tampilan Form Login

Form login merupakan tampilan login agar dapat masuk ke aplikasi. Tampilan form login dapat kita lihat pada gambar 4. berikut ini :

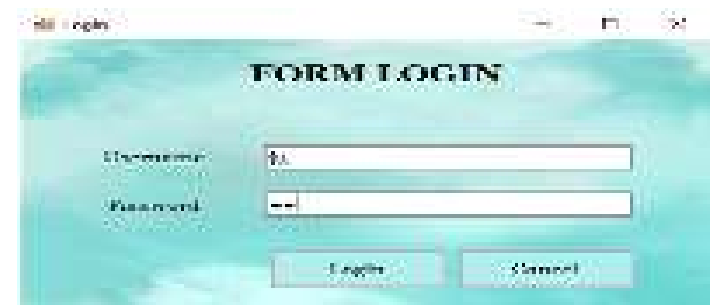

Gambar 4. Form Login

3. Tampilan Form Produk Ikan

Form Produk Ikan merupakan penginputan data produk ikan yang terdapat pada aplikasi. Pada tampilan ini, admin dapat melakukan penambahan, pengubahan, penghapusan data produk ikan. Saat menambah produk ikan, kode produk ikan secara otomatis melanjutkan kode terakhir. Admin juga dapat melakukan pencarian berdasarkan nama produk ikan dengan menekan tombol cari. Jika admin tidak ingin melakukan input data produk ikan, silahkan pilih tombol keluar maka akan kembali pada menu utama. Tampilan form produk ikan dapat kita lihat pada gambar 5 . berikut ini :

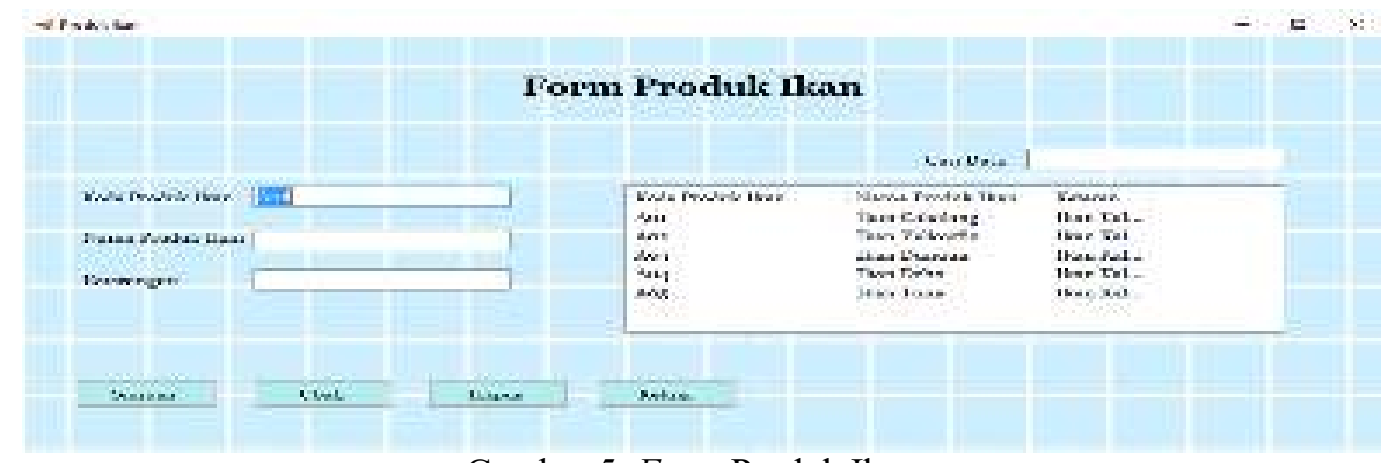

Gambar 5. Form Produk Ikan

4. Tampilan Form Kriteria

Form kriteria merupakan tampilan untuk memasukkan data kriteria yang terdapat dalam aplikasi. dapat kita lihat pada gambar 6 . berikut :

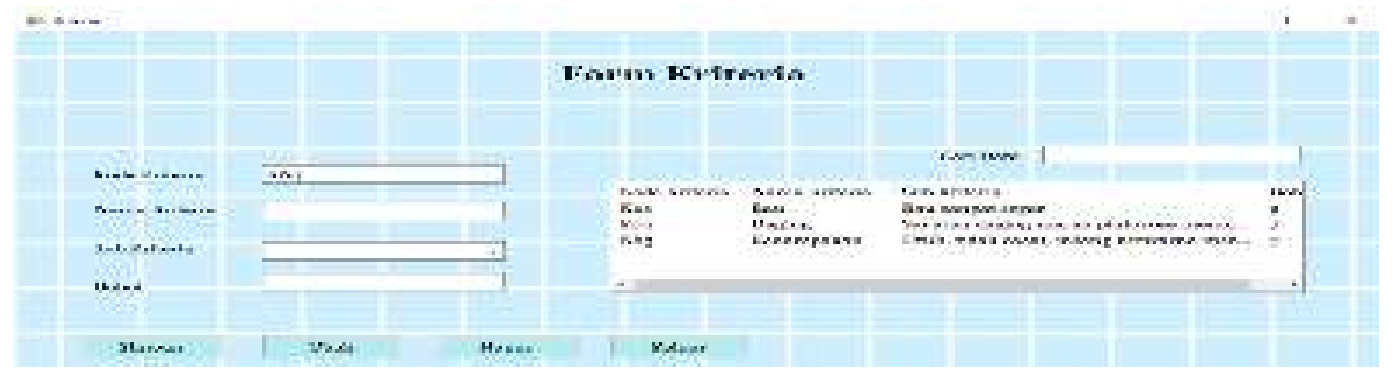




\section{Gambar 6. Form Kriteria}

5. Tampilan Form Promethee

Form perhitungan promethee merupakan tempat proses perhitungan untuk menentukan produk ikan yang layak diekspor pada perusahaan tersebut tersebut. Admin yang melakukan proses perhitungan atau analisa diharuskan untuk memilih kode produk ikan terlebih dahulu, lalu memasukkan nilai berdasarkan kriteria atas data produk ikan. Kemudian memilih tombol input untuk mengetahui sebanyak apa data yang akan di proses untuk menentukan kelayakan sesuai kebutuhan perusahaan. Kemudian memilih tombol proses untuk dapat melihat hasil perhitungan sekaligus akan menyimpannya ke database. Tampilan form perhitungan dapat kita lihat pada gambar 7. berikut ini :

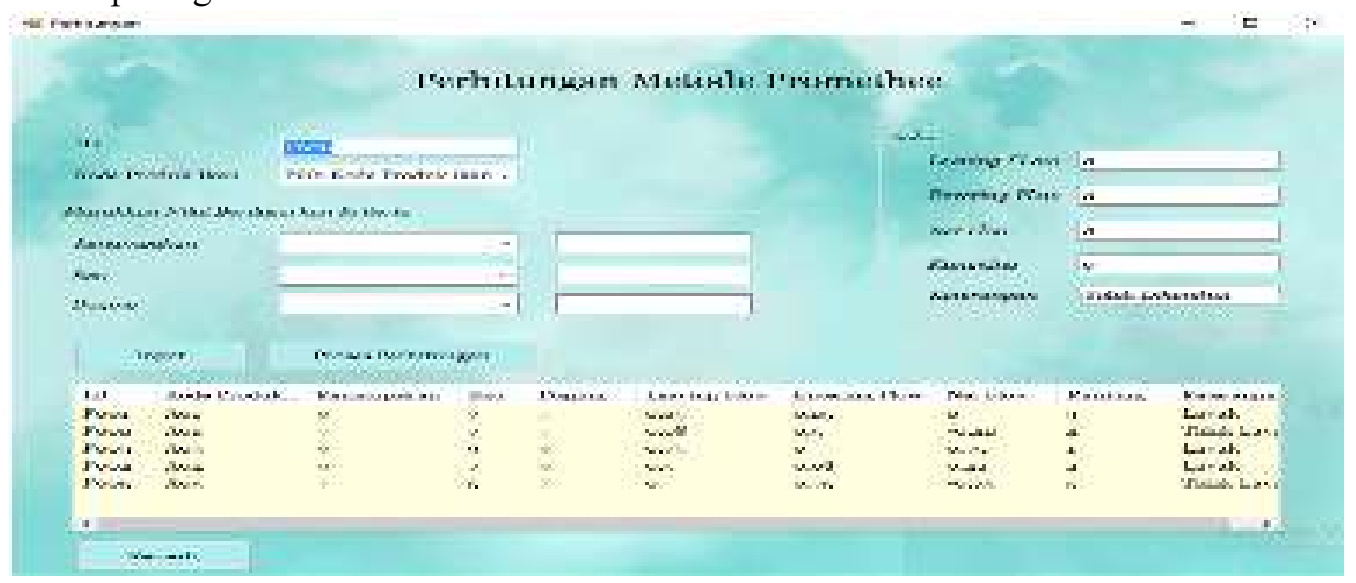

Gambar 7. Form Promethee

6. Tampilan From Laporan

Tampilan ini berisi laporan produk ikan yang layak untuk diekspor dengan menampilkan total nilai perhitungan beserta peringkatnya, sehingga memudahkan untuk pengambilan keputusan. Tampilan laporan dapat kita lihat pada gambar 8 . berikut ini :

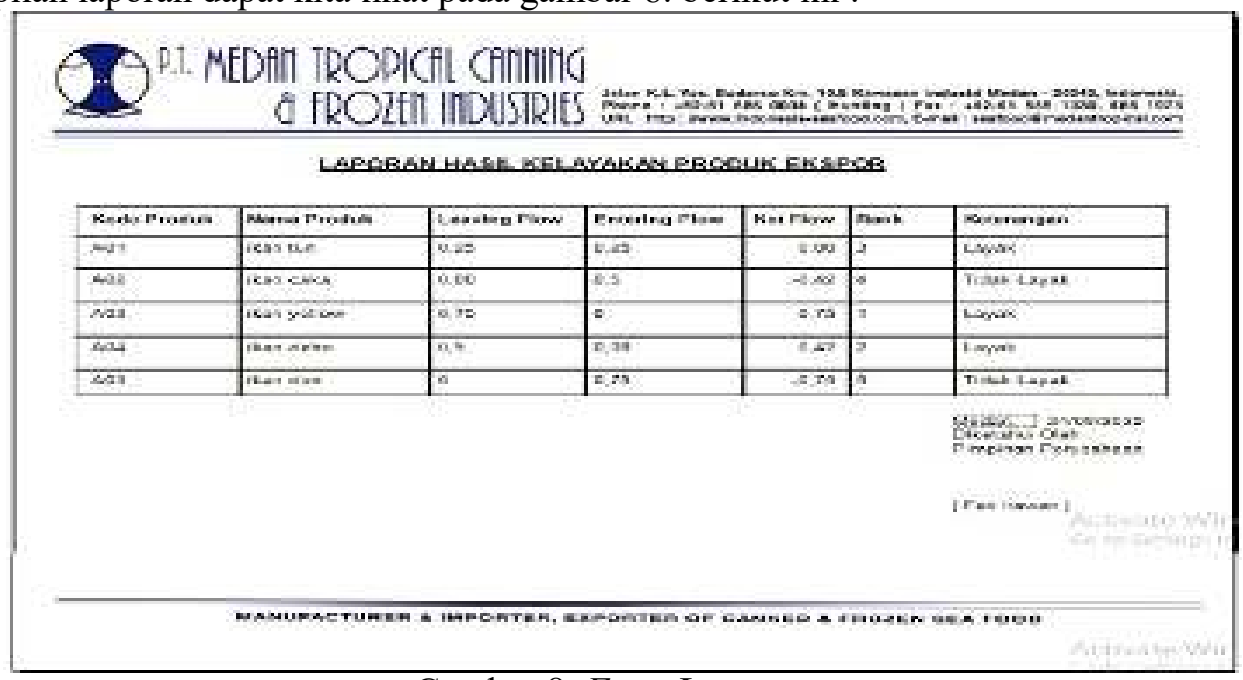

Gambar 8. Form Laporan

7. Tampilan Form About

Form about merupakan tampilan pada aplikasi, menjelaskan latar belakang berdirinya perusahaan. Tampilan form about dapat kita lihat pada gambar 9. berikut ini : 


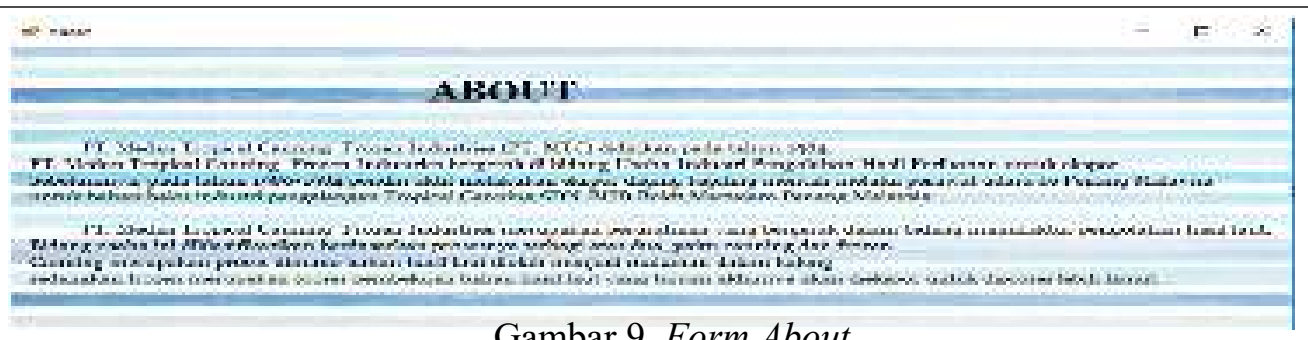

Gambar 9. Form About

\section{Tampilan Form Catalog}

Form catalog merupakan tampilan pada aplikasi yang menjelaskan produk-produk yang akan dijadikan alternatif pada aplikasi. Pada tampilan ini, terlihat berbagai macam produk. Tampilan form catalog dapat kita lihat pada gambar 10. berikut ini :

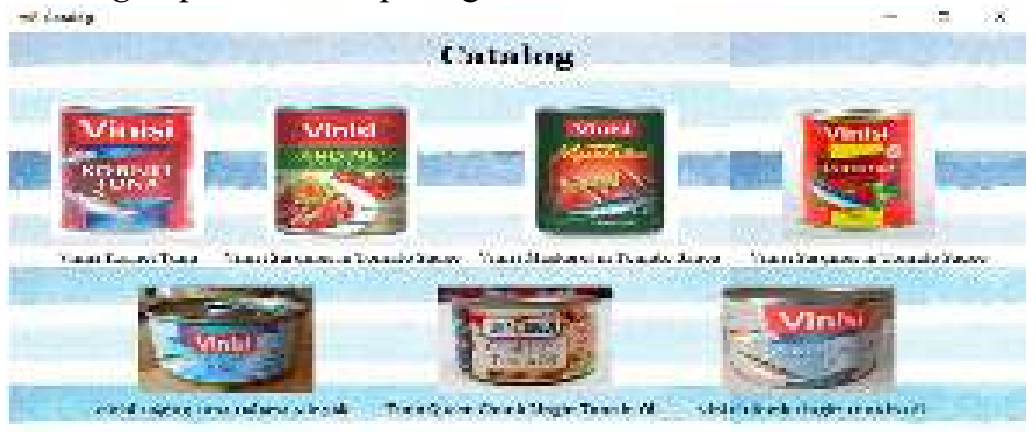

Gambar 10. Form Catalog

9. Tampilan Logout

Form logout merupakan tampilan untuk menonaktifkan akses semua form pada aplikasi. Pada tampilan ini, terdapat dua pilihan yaitu setuju atau tidak untuk keluar dari aplikasi. Tampilan form logout dapat kita lihat pada gambar 11. berikut ini :

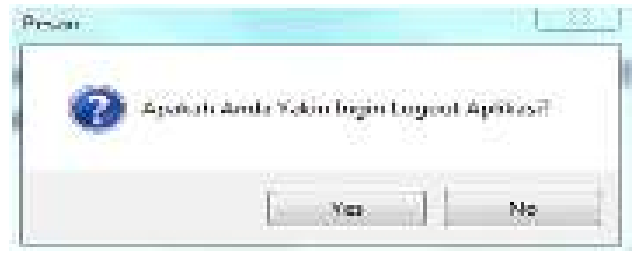

Gambar 11. Form Logout

\section{KESIMPULAN}

Dari hasil penelitian penulis, dapat diambil simpulan sebagai berikut berikut :

1. Dengan menggunakan pemrograman Visual Basic 2010 dan dengan database SQL Server dapat dirancang desain interface yang dinamis dan familiar untuk digunakan dan akurat dalam perhitungan kelayakan produk.

2. Dengan menentukan nilai kriteria dan alternatif untuk mendapatkan nilai maksimum dan minimum dapat diperoleh dan dilanjutkan dengan perhitungan leaving flow, entering flow dan net flow sehingga dapat mengurutkan hasil kelayakan produk dan dapat membantu perusahaan menyelesaikan masalah berdasarkan preferensi yang dipilih.

3. Dengan mengimplementasikan metode perhitungan promethee dalam visual basic untuk mengoptimalkan perhitungan nilai bobot dan kriteria dalam menghitung dan menentukan kelayakan produksi pada perusahaan. 

ini nanti:

Dari kesimpulan, dapat dibuat saran yang akan sangat membantu untuk pengembangan sistem

1. Penerapan metode sistem pendukung keputusan masih perlu diperbaiki untuk meningkatkan performance sistem agar lebih baik lagi untuk kedepannya.

2. Sebaiknya pengembang sistem nantinya dapat membuat grafik yang lebih spesifik dalam pengambilan keputusan data sebagai output dari sistem.

3. Diharapkan untuk penelitian selanjutnya adanya penambahan fitur sehingga sistem tidak hanya digunakan sebagai sistem penentuan saja tetapi bisa digunakan untuk hal lain.

\section{UCAPAN TERIMA KASIH}

Penulis mengucapkan terimakasih yang sebesar-besarnya kepada Universitas Potensi Utama yang telah banyak memberikan masukkan dan saran untuk menyelesaikan penelitian ini.

\section{DAFTAR PUSTAKA}

[1] Ekadiansyah, E., \& Tanti, L. (2014). "Sistem Informasi Geografis Kawasan Berpotensi Minyak Bumi Di Kabupaten Langkat" Sisfotenika, 4(2), 152-162.

[2] Fauzi, M. (2019) "IMPLMENTASI METODE PROFILE MATCHING PADA SISTEM PENDUKUNG KEPUTUSAN DALAM PEMBERIAN JABATAN KELAS PADA MAHASISWA” Jurnal Sistem Informasi Kaputama, 3(1).

[3] Imandasari, T., Wanto, A., \& Windarto, A. P. (2018) "Analisis Pengambilan Keputusan Dalam Menentukan Mahasiswa PKL Menggunakan Metode PROMETHEE" JURIKOM (Jurnal Riset Komputer), 5(3), 234-239.

[4] Karim, J. (2018) "Sistem Pendukung Keputusan Penentuan Prioritas Pembangunan Menggunakan Metode Promethee Pada Desa Ayula Kecamatan Randangan Kabupaten Pohuwato Provinsi Gorontalo" ILKOM Jurnal Ilmiah, 10(1), 86-91.

[5] Kartikasari, Y., Widodo, M., \& Karomani, K. (2015) "KELAYAKAN ISI DAN BAHASA PADA BUKU TEKS BUPENA BAHASA INDONESIA KELAS VII" Jurnal Kata (Bahasa, Sastra, dan Pembelajarannya), 3(4, Apr).

[6] Olivianita, L., Ekojono, E., \& Ariyanto, R. (2016, November) "Sistem pendukung keputusan kelayakan hasil cetakan buku menggunakan metode moora". In Seminar Informatika Aplikatif Polinema.

[7] Safrizal, S., \& Tanti, L. (2015) "Penerapan Metode Promethee Dalam Penyeleksian Siswa Baru (Airlines Staff) pada LPP Penerbangan" Proceedings Konferensi Nasional Sistem dan Informatika (KNS\&I).

[8] Sari, Y. L. (2016) "STUDI DESKRIPTIF HACCP PENGOLAHAN IKAN MANYUNG DI SENTRA PENGASAPAN IKAN BANDARHARJO KOTA SEMARANG TAHUN 2015" (Doctoral dissertation, Universitas Negeri Semarang)

[9] Ulva, A., Iqbal, D., Nuraini, N., Mesran, M., Sutiksno, D. U., \& Yuhandri, Y. (2018, July) "Sistem Pendukung Keputusan Pemilihan Bibit Lele Terbaik Menggunakan Metode MOORA (Multi-Objective Optimization On The Basis Of Ratio Analysis) dan WASPAS (Weight Aggregated Sum Product Assesment)" In Seminar Nasional Sains dan Teknologi Informasi (SENSASI) (Vol. 1, No. 1).

[10] Yudaswara, R. A., Rizal, A., Pratama, R. I., \& Suryana, A. A. H. (2018). "Analisis Kelayakan Usaha Produk Olahan Berbahan Baku Ikan Nila (Oreochromis Niloticus)(Studi Kasus di Cv Sakana Indo Prima Kota Depok)”Jurnal Perikanan Kelautan, 9(1). 